\title{
Subnational Inequality Divergence
}

\author{
Tom VanHeuvelen ${ }^{1}$ \\ University of Minnesota \\ Department of Sociology
}

\begin{abstract}
How have inequality levels across local labor markets in the subnational United States changed over the past eight decades? In this study, I examine inequality divergence, or the inequality of inequalities. While divergence trends of central tendencies such as per capita income have been well documented, less is known about the descriptive trends or contributing mechanisms for inequality. In this study, I construct wage inequality measures in 722 local labor markets covering the entire contiguous United States across 22 waves of Census and American Community Survey data from 1940-2019 to assess the historical trends of inequality divergence. I apply variance decomposition and counterfactual techniques to develop main conclusions. Inequality divergence follows a u-shaped pattern, declining through 1990 but with contemporary divergence at as high a level as any time in the past 80 years. Early era convergence occurred broadly and primarily worked to reduce interregional differences, whereas modern inequality divergence operates through a combination of novel mechanisms, most notably through highly unequal urban areas separating from other labor markets. Overall, results show geographical fragmentation of inequality underneath overall inequality growth in recent years, highlighting the fundamental importance of spatial trends for broader stratification outcomes.
\end{abstract}

${ }^{1}$ Correspondence: tvanheuv@umn.edu. A previous version of this manuscript was presented at the 2021 Population Association of American annual conference. Thank you to Jane VanHeuvelen and Peter Catron for their helpful comments. 
Recent changes in the United States have situated geographical residence as a key pillar of the unequal distribution of economic resources (Austin et al. 2018, Autor 2019, Moretti 2012, VanHeuvelen and Copas 2019). Certain geographical locations, like densely populated cities with a high concentration of college educated workers, tight connections to global markets, and firms driving technological innovation and entrepreneurship have grown apart in their economic fortunes from less populous, less developed places with weaker integration to knowledge work (Glaeser and Gottlieb 2009, Moretti 2012). Such divergence of local labor markets represents a departure from long-run trends of income convergence between regions and between local labor markets dating back over a century (Barro 2008, Ganong and Shoag 2017, Manduca 2019). Thus, as the economic fortunes of high and low paid American workers have diverged in recent decades, so too have the economic fortunes of local labor markets.

Several studies attend to the trajectories of long-run convergence and recent divergence of regions, states, or local labor markets using measures of central tendencies, such as gross domestic product, mean wages, or per capita income (Amos 2014, Ganong and Shoag 2017, Manduca 2019, Storper 2018). However, less well understood are the historical trends of local labor market divergence of economic inequality (but see Clark 2019 for a cross-national study). Although related, divergence trends of mean income and earnings dispersion may follow distinct trajectories, as historical studies of spatial inequality have shown the two to have era-specific nonlinear relationships (Harrison and Bluestone 1988, Lindert and Williamson 2016, Lobao 2016, Moller, Nielsen, and Alderson 2009, Nielsen and Alderson 1997). Furthermore, variation in inequality levels across local labor markets may have significant social, political, and economic implications for society not fully reducible to central tendences, a point illustrated by research on the consequences of state level variation in the minimum wage and social welfare spending on the economic wellbeing of low wage workers (Volscho 2005, Moller, Nielsen and Alderson 2009, VanHeuvelen 2018, Dube 2019). Local inequality variation may be broadly consequential for local systems of economic development and opportunity, as cross-national research has demonstrated the 
dampening effect of high inequality on long term growth (Ostry et al. 2019). Yet little is known about the long-term trajectory of local inequality nor the mechanisms responsible for these changes.

In the current study, I use 22 waves of US Census and American Community Survey data covering eight decades to assess long-run trends in wage inequality convergence between local labor markets. I document the extent to which economic inequality has become more or less similar across local labor markets. Using variance decomposition and counterfactual techniques (Hoffman et al. 2020, Manduca 2019), I document macrolevel trends of inequality divergence and asses the mechanisms underpinning these changes. Inequality converged substantially between 1950 and 1990, but has risen sharply thereafter, resulting in inequality divergence at levels as high as any point studied. Whereas the early era of convergence occurred through broadly shared trajectories and mobilities that resulted in reducing regional inequality differences, the contemporary reversal has been driven by the unique importance of the divergence of highly urban areas from all others. These findings provide novel insights into the nature of spatial inequality in the subnational United States (Lobao et al. 2007), and they highlight the unique challenges faced today of social problems produced by inequality (Mijs and Roe 2021), as the contemporary era not only has uniquely high levels of macrolevel inequality, but a uniquely unequal spatial distribution of inequality across local labor markets.

\section{Background}

The convergence or divergence of economic conditions across the local labor markets making up a national economy has long interested scholars of spatial stratification. Most research on regional inequality has focused on economic measures of central tendencies, such as mean income or GDP per capita. These studies find that the United States experienced a long-term trajectory of economic convergence across places, followed by divergence beginning on some measures in the 1970s (Amos 2014, Barro and Marin 1990, Baumol 1986, Diamond 2016, Lindert and Williamson 2016, Ganong and Shoag 2017, Manduca 2019). Through a combination of migration to economic opportunity, policy intervention, mass expansion of public education, and capital reinvestment in low wage labor markets, 
local labor markets in the United States underwent a steady convergence of mean incomes beginning in the $19^{\text {th }}$ century and extending through the 1970 s, with lower wage labor markets growing quickly to the mean. A substantial portion of this convergence occurred via the US South catching up in development levels to other regions (Ganong and Shoag 2017, Lindert and Williamson 2016, Schulman 1994, Wright 2013). Yet in the last decades of the $20^{\text {th }}$ century, the fortunes of local labor markets have reversed course and begun to pull apart from one another. Scholars have identified a variety of mechanisms responsible for this change, including growth in housing prices among affluent labor markets (Ganong and Shoag 2017), growth of overall earnings inequality (Manduca 2019), declining migration rates (Molloy et al. 2017), deindustrialization and import competition undermining Rust Belt areas built around a small number of employers (Autor et al. 2016), and tighter sorting of educated individuals into a relatively small set of labor markets (Moretti 2012). A unifying theme of these lines of research is that following the deindustrialization and deunionization trends of the 1980s and 1990s (Harrison and Bluestone 1988, Western and Rosenfeld 2011), densely populated urban areas increasingly diverged in terms of educational attainment, economic opportunity, and affluence (Autor 2019, VanHeuvelen and Copas 2019).

Income divergence is an interesting topic in and of itself, as it highlights a parallel between the dispersion of economic fortunes across individual workers and geographical places during an era of rising inequality (Lobao et al. 2016). Income divergence may also both create new social problems and reflect long term social, political, and economic trends that influence the distribution of opportunity in a society (Austin et al 2018, Storper 2018). For example, economic divergence may create a vicious cycle whereby residents of lower income labor markets are priced out of geographical mobility. Income divergence may be partially structured by policy decisions such as state-level variation in the minimum (Volscho 2012), while extreme economic divergence may necessitate substantial government investment to stabilize local economies (Austin et al. 2018). Contemporary divergence trends contribute to the reshaping of local economies, as economists have identified a growing cluster of low paying service jobs, or "wealth work," 
around highly affluent households in affluent urban areas (Autor 2019, Mazzolari and Ragusa 2013). Moreover, those on the losing end of divergence trends may increasingly face declining marriagability and employment among men, increased dependence on non-labor income, increased opioid abuse, and the embrace of extremist politics (Autor 2019, Baccini and Wemouth 2021, Moretti 2012).

\section{Inequality Divergence}

While a substantial amount of research has focused on mean income or per capita income divergence, less attention has been paid to divergence trends of earnings inequality. Although some cross-national research focuses on inequality divergence (e.g. Clark 2019), to the best of the author's knowledge, no study of local labor market inequality divergence within the subnational United States exists. There are at least four reasons to shift attention of divergence research to local labor market inequality.

First, inequality has changed dramatically over the last eight decades (Goldin and Margo 1992, VanHeuvelen 2018). Wage inequality declined substantially during the 1940s, through a combination of unionization, demographic change, a mobilization of manufacturing, increased government spending and broadened social programs, and changes to labor market participation (Lindert and Williamsom 2016). Wage inequality then began to steadily rise from the 1970s onward, through a combination of neoliberal policy changes, pressures from globalization, expansion of financialization, demographic and educational change, the decline of manufacturing, the rise of service and knowledge work, and a decline of union membership and power, to list a few main causes (Neckerman and Torche 2007, Moller 2009, McCall and Percheski 2010, VanHeuvelen 2018). By the 2000s, wage inequality was as high as the previous highwater mark of 1940. Since then, inequality has continued to grow, so that the United States today has as unequal a distribution of wages as at any time in the era of a stable and uniform definition of a labor market (Goldin and Margo 1992). Simply put, growing economic inequality is widely understood to be one of the foundational economic trends undergirding many contemporary economic, social, and political problems and transformations (McCall and Percheski 2010). There is a basic descriptive interest in 
documenting the extent to which local labor markets diverged or converged during this historical era of sharp decline and long rise.

Second, growing inequality may be partially due to diverging per capita income across places. Recent research by Autor (2019) and VanHeuvelen and Copas (2019) show that beginning in the 2000s, wage premiums for high income workers have expanded rapidly across the last half century, especially in affluent labor markets, while wage premiums associated with place have stagnated and declined for lower and middle paid workers. Moreover, growth of high wages has slowed significantly outside of affluent areas, suggesting a narrowing of returns to geographical place over time (VanHeuvelen and Copas 2019). These recent changes represent a stark departure from trends in the mid- and late- $20^{\text {th }}$ century, where even low paid workers in highly affluent "brain hubs" could expect relatively high pay (Glaeser 2009, Moretti 2012). Thus, some of the recent divergence of mean per capita income may in fact reflect changes in the geographical underpinnings of inequality trends, as top incomes diverge more sharply in some places than others (see also Manduca 2019).

Third, there is reason to be skeptical that divergence trends of economic inequality would wholly reduce to trends found for central tendencies. Research by economic historians and stratification scholars documents the nonlinear association between per capita income and economic inequality over the long run of history (Harrison and Bluestone 1988, Lindert and Williamson 2016, Nielsen and Alderson 1997, Milanovic 2016). This research trajectory began with Simon Kuznets who, using a small number of crossnational observations from the early $20^{\text {th }}$ century, speculated that inequality rose and then fell with economic development (1955). In early industrial society, inequality rose with development as a larger share of workers transitioned from low paying and unequal rural and agricultural domains to higher paying, more egalitarian, manufacturing and urban ones. Research largely confirmed these transitions among rich democracies in the early $20^{\text {th }}$ century. As these demographic and economic transitions completed, the inequality-development association reversed, as subsequent increases in development associated with decreasing inequality. Then, beginning around the 1980s, another reversal occurred, as a 
greater share of the population transitioned to the more economically bifurcated service economy, technological innovation allowed for an expansion of globalized trade, and labor and left political power declined. From here on, the most affluent labor markets led a J-shaped takeoff of inequality (Harrison and Bluestone 1988). This “Great Reversal,” or a transition from an inverted-u relationship between inequality and development to J-shaped inequality growth, was confirmed in both cross-national and subnational US studies (Nielsen and Alderson 1997, Moller et al. 2009, VanHeuvelen 2018). Milanovic extended this nonlinear pattern even further with historical data, describing the long historical pattern between inequality and development as a Kuznets Wave, or a sine-curve fluctuation in the long run of history between inequality and economic development (2016). Simply put, there is not a single association between inequality and measures of economic central tendencies. Thus, the long convergence and rapid recent divergence among labor markets for per capita income do not guarantee a similar trend among inequality.

Fourth, variation of inequality levels may translate into diverse social problems across local areas. Perhaps most centrally, divergence of inequality trajectories may result in differential levels of economic growth across local labor markets. Using cross-national data, Ostry et al. provide a compelling account of the way in which growth in economic inequality, especially at high levels, has a robust dampening effect on a country's economic growth (2019). Other cross-national research highlights the broad social problems that are associated with high inequality growth, from health to education to crime (Wilkinson and Pickett 2011), while US-centered research shows inequality to translate into a wide number of social problems, such as segregated social networks, residential income segregation, happiness inequality, and declining intergenerational mobility (Reardon and Bischoff 2011, Hout 2016, Chetty et al. 2018, Mijs and Roe 2021). Should inequality growth across local labor markets in the United States undergo rapid rates of divergence, one might reasonably expect these changes to produce differential risks across places for economic, social, and political problems.

\section{National-, Regional-, and Urbanized-Inequality Divergence}


In this paper, I describe aggregate trends of inequality divergence. Then, I assess the contribution of national, regional, and local characteristics to these trends. Because few studies have examined inequality divergence in the subnational US, I borrow from the methodological logics used in studies of central tendencies and apply them to the case of inequality. I first focus on two geographical mechanisms that may channel overall trends. I then reassess trends using counterfactual analyses to assess macrolevel shifts in the earnings distribution (Manduca 2019).

First, divergence trends may occur unevenly across regions. The South catching up to the rest of the country played a central role in long-run historical trends of economic development and per capita convergence through the mid-20 $0^{\text {th }}$ century (Lindert and Williamson 2016, Gonang and Shoag 2017). Through a combination of the reliance on agricultural employment, entrenched racial discrimination, slow manufacturing uptake, deep and entrenched poverty, and political unity against labor rights, the US South lagged behind other regions in economic development. Although the US South today remains poorer compared to other regions (Baker 2020), it has experienced significant convergence in its economic development to other US regions. Historical studies have documented the mechanisms of Southern convergence such as federal-level policies aimed at economic growth, expanded social welfare policies to address poverty, and expanded employment opportunities to racial minorities following Civil Rights legislation (Lindert and Williamson 2016, Schulman 1998, Wright 2013). Conversely, many labor markets in the Midwest and Northeast in the Rust Belt have recently experienced substantial hardships associated with deindustrialization. Many moderately and small-sized labor markets relied on a small number of large manufacturing employers to provide their labor market's economic lifeblood. Deindustrialization and deunionization, both of which accelerated in the 1980s, undermined the local economic foundation of many labor markets in Rust Belt areas. As Moretti details (2012), this change rippled to negatively affect adjacent industries, and Autor et al. shows that workers remaining in such places tended to be negatively impacted multiple times by these shocks (2016). The most vulnerable 
tended to be least able to escape these places for better economic fortunes. All considered, it is sensible to anticipate that overall inequality divergence be partially channeled through interregional processes.

Second, local labor experienced radically different fortunes in the past several decades based on their level of urbanization. Stratification scholars have observed that in the $21^{\text {st }}$ century, populous and dense urban labor markets have separated from others. Agglomeration and network effects, complex and diversified economies, and tight connections to global networks has proven to be highly lucrative as the economy has shifted to privilege and reward knowledge work, while more rural and less populous areas in general face pronounced risks of being left behind, aging populations, stagnant or declining educational attainment levels, and underdeveloped knowledge economies. Recent work by Autor (2019) and VanHeuvelen and Copas (2019) also show that inequality is increasingly concentrated among densely populated metropolitan places, as top incomes in these locations are increasingly separating from others, and the agglomeration effect of urban residency is increasingly narrowing to all but the top wage earners. Thus, places defined by urbanization may experience pronounced differences in inequality driven by top earning workers, resulting in higher inequality divergence across local areas.

After assessing how inequality divergence occurs through regional and local areas, I next turn to assess how macrolevel changes to the earnings distribution contribute to inequality divergence. To do so, I draw on the methodological logic developed by Manduca (2019). He considers two mechanical changes that could affect the nature of local labor market per capita income divergence. First, divergence may be driven by geographical mobility of wage levels across labor markets. If all high-earners relocate and become more concentrated in a small number of local labor markets, per capita divergence would be driven partially by microlevel mobility decisions. ${ }^{2}$ In contrast, such sorting by wage levels may result in inequality convergence, akin to how highly unequal metropolitan areas can have low within-

\footnotetext{
${ }^{2}$ Specifically, Manduca studies the relocation of wage percentiles, not individuals holding particular wages. Several longitudinal studies of geographical mobility reveal that individual wages increase following movement to lucrative labor markets (e.g. De la Roca and Puga 2017). This simulation thus assesses the geographic mobility of where, for example, high wage levels are attained.
} 
neighborhood inequality created through income segregation (Reardon and Bischoff 2011). Although intercounty and interstate mobility has declined substantially since the 1980s (Molloy et al. 2017), given that contemporary inequality trends are driven primarily by the separation of higher paid workers from the middle of the distribution (Autor 2019), any remaining geographical wage mobility in the modern era may nevertheless contribute to increase divergence.

Second, changes to the national earnings distribution might drive local labor market divergence. Given that overall inequality growth in recent decades has been driven primarily by top income earners separate from others (Acemoglu and Auto 2011), such overall inequality change may translate into separation of inequality levels across local areas based on their preexisting distribution of individual workers. For example, Boston and New York may have consistently high proportions of high-income workers. If national economic conditions change so that high-income workers separate from others, these local labor markets may experience per capita divergence because of the preexisting stock of high income workers and national trends of high income divergence. They may also experience inequality divergence, as they would experience disproportionate inequality growth compared to other labor markets that had fewer high earning workers. In this way, local labor market inequality divergence is a partial byproduct of national inequality trends.

\section{Data}

I use data from 22 waves of US Census and American Community Survey (ACS) data between years 1940 and 2019. These data provide the most comprehensive and high-quality historical information of individual wages and geographical location available for researchers.

The 1940 Census wave presents a sensible starting point for the current study. The final states to join the contiguous United States, Arizona and New Mexico, were incorporated in 1912. Thus, a stable set of geographic areas over time could begin as early as the 1920 Census wave. Unfortunately, the 1920 and 1930 Census waves lack microlevel income information. Historical sociologists studying this period 
effectively deploy occupational income scores based on median incomes of occupations in 1956 (e.g. Catron 2019). Although this approach is appropriate to study macrolevel associations of central tendencies, it is inappropriate for the current study. Applied to the study of spatial inequality, these occupational income scores can only reveal the compositional difference across local labor markets and the typical earnings difference across occupations, they cannot identify regional variation in returns to occupations, nor can they identify wage variation within occupations, a central component to overall inequality levels (Mouw and Kalleberg 2010). The 1940 Census provides the earliest wave with a coherent definition of labor force participation and microlevel earnings measurements, thus making it a reasonable starting period to assess historical convergence trends (Goldin and Margo 1992).

Following previous research on subnational spatial inequality (Autor and Dorn 2014, Chetty et al. 2018, VanHeuvelen 2018, 2020, VanHeuvelen and Copas 2019) and income convergence (Manduca 2019), I sort respondents into 722 local labor markets, commuting zones, which cover the entire contiguous United States (see Tolbert and Sizer 1992; Dorn 2009 for more details). Briefly, commuting zones are Census-defined time-consistent collections of counties developed from journey to work data, with more commuting between home and work within a commuting zone than across two commuting zones. For example, more individuals commute between Kings and Queens counties within the New York City metro area than between Kings county and Tompkins county, the location of Ithaca, NY. I use the 1990 definition of commuting zones, which provides the most fine-grained measurement and largest number of commuting zones.

To measure inequality within commuting zones, I construct hourly wage information for working-aged individuals. While many studies of per capita income divergence use household income, I measure inequality using hourly wages for four reasons. First, many studies of historical inequality growth focus on individual measures, such as wages or earnings (e.g. Margo 1992, Western and Rosenfeld 2011, Autor 2020). Measuring wages directly connects the current study to this existing stock of inequality studies. Second, analysis of wages of pre-tax and transfer incomes avoids several practical 
problems, such as changes to tax and transfer regimes over time as well as how to handle elderly household income before and after substantial policy changes of the 1960s (Iceland 2013). ${ }^{3}$ This point is especially important as many commuting zones overlap state boundaries, complicating the precise measurement of local tax and transfer regimes. Further, local tax and transfer information from standard imputation procedures, such as the NBER taxsim program, is not available prior to 1977 . Third, scholars have identified wage inequality as the main stock of money contributing to overall household income inequality, especially among the bottom 95 percentiles (Western and Rosenfeld 2011). While a focus on wage inequality has important limitations - including changes to hours worked, pooling of earnings within households, and inequality stemming from sources other than employed labor-wages nevertheless represent a foundational unit for inequality measurements. Finally, the 1940 wave of the Census presents difficulties for calculating other economic measures such as household income. Respondents provide their labor earnings but not detailed information on other forms of income, such as self-employment income, transfer income, or business income. Thus, one must choose whether to omit 1940 from analysis to focus on household income or keep the 1940 wave and focus on wages.

Wage inequality is collected from respondents aged 16-64 who have a non-zero amount of work hours, who are not in group quarters, and who are not self-employed. I adjust wages for inflation to 2011 dollars using the Bureau of Economic Analysis' personal consumption expenditure tables. To avoid both introducing bias into results from workers only marginally attached to the labor market and creating some arbitrary cutoff for part time employment, I use a survey weight that is the product of the weight provided by IPUMS and a workers' annual work hours relative to 1,200 (Autor and Acemoglu 2011). This decision allows for the inclusion of individuals who are only partially attached to the labor market without risking that results are overly distorted by unusual wage levels of these respondents. I compute individual wages as total annual income from wages, salary, commissions, bonuses, or tips from all jobs, divided by annual hours worked. Wages are bottom-coded at $1 \frac{1}{2}$ the federal minimum wage and top-coded approximately to

\footnotetext{
${ }^{3}$ Of course, policy and taxation regime can influence prefisc earnings distributions.
} 
1.5 times the year-specific maximum value. ${ }^{4}$ Then, I compute Gini coefficients from respondent wages in each commuting zone.

\section{Methods}

I take three main approaches to assessing wage inequality divergence across local labor markets.

I begin by computing a standard statistic of overall divergence: sigma divergence. Sigma divergence refers to change over time in the variability of outcome measures across local areas. Put differently, it is a measure of the inequality of inequalities (Clark 2019). I compute sigma divergence using the variance of Gini coefficients in a particular wave. Wage Gini coefficients change substantially in their mean values over time, risking biased estimates of variance measures. Therefore, I also compute the coefficient of variation, or the standard deviation divided by the mean (Beckfield 2009). A comparison of the variance to the coefficient of variation helps guard against the possibility that trends from main results simply reflect periods that have overall high or low inequality levels.

A main alternative to sigma divergence is beta divergence, or the rate at which local areas with lower values of the outcome under consideration "catch up" to other areas. Beta divergence can be modeled by predicting change in an outcome against its initial value. As formally described by Young et al. (2008), sigma and beta divergence measures are related, but one need not find full agreement across the two measures. ${ }^{5}$ The influence of beta divergence on sigma divergence can be muted or reversed through idiosyncratic shocks unrelated to the central tendency of the association between lagged inequality values and inequality change. Beta divergence is thus necessary, but not sufficient, for sigma

\footnotetext{
${ }^{4}$ From 2000 onwards, states vary in their maximum income value. I use a roughly standardized top-coded income to ensure that results are not biased from time varying place varying top codes (Autor and Dorn 2013).

${ }^{5}$ Specifically, they show that beta divergence, written as $\ln \left(\frac{y_{i t}}{y_{i}, t-1}\right)=\alpha-\beta \ln \left(y_{i}, t-1\right)+\mu_{i}$ can be incorporated into sigma convergence when written as $\sigma^{2}=\frac{\sigma_{u}^{2}}{\left[1-(1-\beta)^{2}\right]}$. Put differently, greater variance of the error term in the beta convergence equation can outpace the overall association between lagged inequality values and inequality change. Because there is no reason to believe these shocks are random or immaterial to overall trends, I focus on sigma divergence.
} 
divergence. Because overall spatial and individual trends are likely driven by labor markets with extreme values, it is more appropriate to focus on sigma divergence. In the Results, I include footnoted discussions of beta divergence measures when they lead to different results.

After assessing divergence among all commuting zones in the contiguous United States, I assess the contribution of heterogeneity across regions and labor markets with different levels of urbanization. I differentiate four Census regions, Northeast, Midwest, South, and West. Identifying urban areas presents some conceptual complexity, as some labor markets have changed in their density, population sizes, and relative ranking since $1940 .{ }^{6}$ To make a time-stable definition, I construct a scale using principal components analysis of the commuting zone-specific mean values of population size and population density and sort commuting zones into five groups, ranking from most to least urban. Example labor markets in each group are listed in the Appendix.

I next reassess sigma convergence across these geographical groupings by applying the logic of variance decomposition to determine the contribution of mean inequality differences across areas and variation of inequality within areas. In the simplest case, consider a basic regression model with a single binary regressor:

$$
y_{i}=\delta x_{i}+\epsilon_{i}
$$

The variance of y can be written as (Hoffman et al. 2020):

$$
\operatorname{Var}(y)=\delta^{2} \theta(1-\theta)+\theta \sigma_{1}^{2}+(1-\theta) \sigma_{0}^{2}
$$

Where $\theta$ is the proportion of the sample in $\mathrm{x}=1$ and $\sigma_{0,1}^{2}$ are the residual variances among groups $\mathrm{x}=0$ and $x=1$. Total variance of $y$ is thus a summation of [1] the between group difference of $y$ across groups $x=0$

\footnotetext{
${ }^{6}$ While studies differ in the characteristics identified as the drivers of change, many studies of spatial inequality identify mechanisms associated with urbanization as key drivers of contemporary stratification processes. Although alternative dimensions, such as proportion of college degree holders, concentration of service work, or high wage levels, could be used instead, sensitivity analyses showed that population differences tended to be more stable over time than these alternative measures.
} 
and $x=1$ and [2] the proportionately weighted residual variance of $y$ within categories $x=0$ and [3] $x=1$. Moving beyond this simple example introduces some complexity that motivates rewriting the variance decomposition formula. A useful generalization can be built on a simpler definition of the composition of the variance of the dependent variable, $y$, as the sum of the predicted and residual portions of a regression model:

$$
\begin{aligned}
& \operatorname{Var}(y)=\operatorname{Var}(\hat{y})+\operatorname{Var}(\epsilon) \\
& \operatorname{Var}(y)=\operatorname{Var}(\text { Betwen })+\operatorname{Var}(\text { Within })
\end{aligned}
$$

Because $\operatorname{Var}($ Between) is simply the variance of the outcome predicted by one's specified regression model, and because the sum of the residual variance is the weighted summation of the variance across mutually exclusive categories (Western and Bloome 2009, Hoffman et al. 2020), the variance decomposition motivating this section can be rewritten as:

$$
\operatorname{Var}(y)=\operatorname{Var}(y) R^{2}+\sum_{c=1}^{C} \theta_{c} \sigma_{c}^{2}
$$

That is, the total variance of $\mathrm{y}$ is the linear combination of the between-group variation of $\mathrm{x}_{1}$, defined as the product of the variance of $y$ and the model R-squared value, and the sum of the category-specific products of category proportions and the category-specific residual variance. In a simple case of two continuous variables, $\mathrm{x} 1$ and $\mathrm{x} 2$, or a single three-category variable, $\mathrm{x} 3$, the unique contribution of between-group variances attributable across variables or across categories would simply be written as:

$$
\operatorname{var}(\text { Between })=\beta_{1}^{2} \operatorname{Var}\left(x_{1}\right)+\beta_{2}^{2} \operatorname{Var}\left(x_{2}\right)+2 * \beta_{1} * \beta_{2} * \operatorname{Cov}\left(x_{1}, x_{2}\right)
$$

This decomposition becomes much more complicated with two multicategory variables used to compute the between-portion of variance, introducing a substantial number of covariances whose substantive meaning to sigma divergence are unclear. To simplify the computation of between-group variance attributable to regional and urbanization characteristics, I use a Shapley decomposition technique, developed and formalized by Shorrocks (2013). Shapley decomposition was motivated by the Shapley 
value from cooperative game theoretics, and involves computing $\mathrm{R}^{2}$ contributions for independent variables across all possible sequential combinations of adjustment for a set of independent variables. ${ }^{7}$ Thus, overall $\mathrm{R}^{2}$ values, or the between group contribution to total variance, can be divided into contributions from regional and urbanization characteristics, resulting in the following decomposition:

$$
\operatorname{Var}(y)=\operatorname{Var}(y) R_{\text {region }}^{2}+\operatorname{Var}(y) R_{\text {urbanization }}^{2}+\sum_{c=1}^{C} \theta_{c} \sigma_{c}^{2}
$$

I decompose total variance into three distinct components: [1] a between-region component [2] betweenurbanized area component [3] within region or urbanized area component. ${ }^{8}$ When this decomposition is run in separate time periods, components [1], [2], and [3] from a baseline period can be imputed into future waves, and the proportional difference in total variance indicates the relative importance of that component to trends in sigma divergence (Western and Bloome 2009).

Next, I compute counterfactual simulations to assess the contribution of aggregate mechanisms to convergence trends over time. Following the logic developed by Manduca for local labor market per capita income divergence (2019), I compute two sets of counterfactuals. For each counterfactual trend, I use two baseline periods for comparison: 1940, the first wave of observation, and 1980, the decade marking the full beginning of the contemporary upswing of macrolevel inequality.

First, I assess the importance of change in the geographical distribution of wage percentiles held by workers. I sort wages from a specific Census or ACS wave into 50 quantiles using all working aged respondents regardless of commuting zone location. ${ }^{9}$ Then, I use a reweighting technique developed by

\footnotetext{
${ }^{7}$ A rough approximation of a Shapley decomposition for $\mathrm{x}_{1}$ and $\mathrm{x}_{2}$ would be the mixed $\mathrm{R}^{2}$ values first from regressing $\mathrm{x}_{1}$ on $\mathrm{y}$, and then regressing residualized-via- $\mathrm{x}_{2} \mathrm{x}_{1}$ on residualized-via- $\mathrm{x}_{2} \mathrm{y}$.

${ }^{8}$ There is no simple way to combine within-group variation of urban area and region, as these categories overlap without assessing region-by-urbanized areas. I examine these sets of variables separately when examining withingroup variation.

${ }^{9}$ Sensitivity analyses showed that using more than 50 quantiles tended to create problems of sparse cells in logistic regression models.
} 
Dinardo, Lemieux, and Fortin to reweight the distribution of wage earners in a Commuting zone at time $\mathrm{t}$ to be identical to that in time t-1 (1996). The reweighting formula is written as:

$$
\text { Reweight }_{y i}=\pi_{y i} *\left(\frac{p_{y i}}{\left(1-p_{y i}\right)} / \frac{\mu_{y}}{\left(1-\mu_{y}\right)}\right)
$$

I estimate logistic regression models with wage quantile categories separately by commuting zone with the baseline Census wave paired with each subsequent Census or ACS wave between 1950-2019, or a total of 15,162 regressions (722 commuting zones across 21 census waves). I use these to compute the probability that a particular wage quantile is in the non-1940 census wave. Then for each particular nonbaseline year, $y$, I multiply the person-specific survey weight, $\pi_{y i}$, by the individual specific predicted probability of being in baseline year, $p_{y i}$, divided by the proportion of respondents in waves paired with the baseline year, $\mu_{y}$. These new survey weights create identical distributions of respondents in each year relative to the concentration of wage quantiles in baseline year. I then use these reweighted samples to compute Gini coefficients and wave-specific variances of Gini coefficients.

Second, I recompute sigma divergence after adjusting the national wage distribution to 1940 levels. To do so, I divide the country-level wage distribution into 100 quantiles and estimate the ratio of each wage quantile relative to the country-level mean wage. ${ }^{10}$ I use the ratios computed in the baseline Census wave and the subsequent wave-specific mean wages to recompute wage quantile values in these subsequent waves. I then recompute commuting zone-specific Gini coefficients using these quantile wage values and reestimate wave-specific variances. The two counterfactual sigma divergence measures are then compared against the observed levels of sigma divergence. A larger relative difference between observed and counterfactual sigma divergence levels indicates greater relative importance of the particular mechanism to inequality divergence trends.

\footnotetext{
${ }^{10}$ I replicated results using 50 quantiles but found similar results. Because the national sample size is larger than commuting-zone specific samples, I do not run into the issue of sparse cells as in the first counterfactual.
} 
Finally, I recompute the decomposition of variance by region and urbanization using counterfactual trends and compare results to decompositions of observed trends. The difference of the relative contribution of between- and within-place portions of the variance identity the geographical mechanisms contributing to the differences between counterfactual and observed measures of sigma convergence.

\section{Results}

I begin by assessing overall trends of sigma convergence, or the year specific variability of wage Gini coefficients. Figure 1 shows trends for both the variance and the coefficient of variation with bootstrapped standard errors. ${ }^{11}$ The variance increased between 1940 and 1950, from about 0.08 to 0.11 . Then, between 1950 and 1990, I observe that the variation of local inequality declined substantially, with the variance reducing in magnitude by about $60 \%$, from about 0.11 in 1950 to around 0.04 in 1990 . After 1990, Gini coefficients diverged again, rising from about 0.04 to 0.1 in the most recent ACS waves. ${ }^{12}$ Figure 3 thus reveals a u-shaped pattern in sigma convergence. The inequality of inequalities shrunk during the era of inequality decline, and its growth lagged behind the renewed growth of individual wage inequality in the 1980s and per capita divergence beginning in the 1970s. By the end of the 2010s, the magnitude of sigma divergence returned to a magnitude nearly as large as in any period under study.

[Figure 1 About Here]

\section{Regional and Local Contributors to Inequality Divergence}

What contributed to inequality convergence through 1990 and the steep rise thereafter? I next decompose total Gini coefficient variance into geographical components to assess how these overall trends occurred. Figure 2 includes results that decompose total sigma divergence into three components:

\footnotetext{
${ }^{11}$ Beta convergence measures showed substantial convergence between 1940 and 1980, with little trend between 1980 and 2019. Thus, the recent upswing of sigma convergence has occurred on the tails of the Gini coefficient distribution, beyond the central tendency.

${ }^{12}$ Note that the coefficient of variation and the variance provide largely similar trends until 2010 onward. In this period, with a higher mean inequality level, the variance indicates a steeper rate of divergence.
} 
[1] variance due to between-region differences in Gini coefficients [2] variance due to between-urbanized area differences in Gini coefficients and [3] within group variance among either regions or urbanized areas.

[Figure 2 About Here]

[Figure 3 About Here]

Figure 2 shows that the spike in inequality variance during the 1940s was primarily driven by interregional differences. Figure 3, which shows mean inequality levels across regions and urbanized areas, reveals how this interregional contribution occurred. The West, Midwest, and Northeast experienced dramatic declines in mean inequality levels, from about .34 to about .29 , while the South underwent a much more modest decline in inequality, from about .345 to about .32 . Three main factors can explain the inequality convergence between 1950 and 1990. First, inequality converged within urbanized areas at roughly uniform rates (Figure 2). Inequality converged at slightly higher rates in the least urbanized areas, but this reflects slight variation around the more general story of broadly shared within-place convergence. Second, inequality converged within the South, West, and Midwest regions, with the South undergoing substantial convergence beginning in the 1940s and lasting through 2000. Third, between-region inequality differences were critical for inequality convergence through 1990, yet the process of this convergence occurred in the inverse direction of that typically documented in studies of economic development. Whereas the South "caught up" with economic development levels to the rest of the country following the 1960s (Ganong and Shoag 2017, Schulman 1998), the rest of the country "caught up" to the overall high Southern inequality levels during this same period. All other regions underwent rapid growth of mean wage inequality after 1950, while the US South held at high and stable mean levels through 1980, after which mean Southern inequality grew in ways similar to other US regions. 
The reversal of inequality convergence through 1990 to inequality divergence thereafter can be attributed to two general factors. First, between-region and -urbanization both contributed to increasing divergence after 2000. The between-urbanization contribution is especially noteworthy. After contributing essentially nothing to sigma divergence through 1990 , it accounted for approximately $20 \%$ of total variance growth by the last waves of study. Figure 3 shows that the between-urbanization contribution occurred almost entirely by the distinct growth of inequality among highly urban areas. ${ }^{13}$ Similarly, interregional differences grew in importance, its contribution changing from about $10 \%$ of total variance to about $20 \%$ between 1990 and 2019. Notably, the Midwest has become the primary contributor to interregional variance since the 2000s, with this region having lower mean inequality values compared to the others. Second, within-region and within-urbanization variance grew in importance in the 2000s. Within-Midwest variance increased to the highest contributions since 1940, while within-West variance increased to return to its relative contribution in 1940. The US South, although having much lower variance compared to early waves, has grown in its contribution to overall trends relative to its substantial convergence influence through the 1980s. Similarly, while all urban and rural regions experienced decline of variance through 1990, all returned to their relative contributions as observed in 1940.

In total, two conclusions can be drawn for convergence through 1990 and three for divergence in the $21^{\text {st }}$ century. First, convergence occurred broadly, across rural and urban areas, as well as across most regions. While the magnitude of the contribution varies, with greater impact among more rural places and among the South, for example, the more fundamental trend is one of a broadly shared convergence.

Second, inter-regional convergence contributed to overall convergence, although the mechanism is the inverse of that found among development. Whereas Southern inequality stabilized, other regions grew in their inequality and "caught up" to higher Southern inequality levels. This trend represents the mirror image of the Southern developmental convergence catching up with the rest of the United States.

\footnotetext{
${ }^{13}$ Sensitivity analyses show the divergence primarily occurs among commuting zones with the highest urbanization levels.
} 
Regarding contemporary divergence, firstly, the separation of highly unequal, highly urban areas from all others has helped push divergence trends upward. This contribution represents a unique input into contemporary divergence trends compared to those driving trends in the $20^{\text {th }}$ century. Second, interregional inequality has reemerged as an important contributor to overall inequality divergence, but through a different mechanism. Whereas early $20^{\text {th }}$ century interregional inequality reflected high inequality in the US South, early $21^{\text {st }}$ century interregional inequality reflects relatively low inequality among the Midwest. Third, within region and urbanized area contributions have returned to their absolute levels of 1940, collectively pushing up overall inequality variance. While some meaningful variation across places can be detected, the fundamental trend is one of broadly shared increase in inequality variance.

\section{Nation-Level Counterfactuals}

To interrogate the contribution of macrolevel trends to the u-shaped pattern of inequality divergence, Figure 4 shows results from counterfactual simulations holding the national wage distribution and the geographical distribution of wages at baseline years of 1940 (left column) and 1980 (right column). Two conclusions can be drawn from counterfactual results compared to the 1940 baseline. First, from 1960 onward, predicted sigma divergence would have been substantially larger had the geographical distribution of wage earners remained at its 1940 levels. The bottom panel shows simulated divergence compared to observed levels by survey wave. Holding the geographical distribution of wage earners at their 1940 locations would have increased the variation of inequality across local labor markets by a factor of 3 in 1980. A sizable portion of inequality convergence that occurred through 1980 across local areas resulted from the geographic relocation of wage percentiles across local labor markets, a rough proxy for geographical mobility. Note that the most sizable contribution of geography occurred during the 1960-1980 era, with the relocation of wage percentiles during this era resulting in a sizable compressing effect. These results suggest that part of this historical convergence across local areas through the end of the $20^{\text {th }}$ century resulted from an equalizing sorting of wage earners across local labor markets. 
[Figure 4 About Here]

Second, I find that predicted inequality divergence would have been modestly lower had the distribution of national wages relative to mean wage levels remained at 1940 levels. The contribution of the national distribution of wages to sigma divergence has grown since 1990, suggesting that the nature of the upswing of inequality at the national level from about 2000 onward contributed to the growth of inequality divergence across places. Compared to mobility, however, the national distribution of wages has far less of an impact over the entire period under study.

As shown earlier, inequality convergence bottomed out in the 1980 and 1990 waves, the period when modern inequality growth began in earnest. I replicate counterfactual simulations using 1980 as the baseline, shown in the right column. Similar to results of per capita income by Manduca (2019), I find that changes to the national wage distribution relative to 1980 have had a sizable impact on inequality divergence in recent decades. Had the wage distribution in 2019 mirrored its position to mean income found in 1980, the variation of wage inequality across local labor markets would have been about $40 \%$ lower. Regarding geographical mobility, I find little substantive contribution to divergence trends until after the Great Recession. Holding the geographical distribution of wage earners to 1980 levels would have at most reduced the spread of local labor market inequality by $10 \%$ up until the Great Recession. However, mobility relative to 1980 has increased in importance through the 2010 s, with simulated divergence $30 \%$ lower in the most recent time period. Following the Great Recession, a combination of superstar cities diverging from other locations (Moretti 2012, Autor 2019), a concentration of rewards accruing within these superstar cities (VanHeuvelen and Copas 2019), and additional factors such as housing costs (Gonang and Shoag 2017) resulted in the simultaneous concentration of high earners in a small subset of labor markets and the separation of these high earners from others in those labor markets. Notably, geographic and national distribution factors move in the same direction for the first time in the period under study following the 2010s. Through the $20^{\text {th }}$ century, geographic mobility and wage 
distributional changes pulled in opposite directions, counteracting the influence of either for overall divergence trends. ${ }^{14}$

Why did national geographic and wage distribution effects channel into inequality divergence trends? Tables 1 and 2 present the decomposition techniques used in Figure 2, applied across observed and counterfactual inequality variances. The top half of these Tables show change in variances across two key time periods, 1940 to 1980 and 1980 to 2019. Total change is decomposed into between-region and urbanization components, as well as either within-region or -urbanization components. The bottom half of these tables shows second differences, or the difference between time changes across counterfactual and observed trends, as well as the proportion of each between- and within-component contributing to the overall second difference.

I focus on the percent contributions of the between and within components across counterfactual conditions. For the substantial convergence between 1940 and 1980, shown in Table 1, the sizable influence of geographical mobility was primarily channeled through two processes: interregional differences (30\% of the total difference between observed and counterfactual) and within-South differences (about $25 \%$ of the total difference). Within-urbanization effects have roughly similar magnitudes, while between-urban effects contribute negligibly to differences between counterfactual and observed trends. Although there is little difference between observed trends and those through the national wage distribution counterfactual, results again point to the primary importance of interregional changes and changes in the US South. Thus, the substantial decline of inequality variance through the 1980s largely occurred through geographical mobility, with these effects primarily operating to reduce interregional inequality differences and equalize inequality levels across Southern labor markets.

\footnotetext{
${ }^{14}$ The appendix includes a visualization of the nature of wage quantile changes across time. The recent era is unique in the substantial growth of high wage levels relative to all others. Thus, the recent importance of geography and national wage distributional changes are primarily occurring among the highest wage earners.
} 
Table 2 shows results for the increase of inequality variance between 1980 and 2019. As shown in Figure 4, both geographical mobility and changes to the national wage distribution contributed at similar magnitudes to overall divergence trends. Table 2 shows that these trends were substantially channeled through between-urbanization effects, with about $22 \%$ of the national wage distribution counterfactual and $36 \%$ of the geographical mobility counterfactual attributable to the betweenurbanization component. That is, the relocation of wage percentiles and the nature of the growth of overall wage inequality in the $21^{\text {st }}$ century have influenced inequality divergence largely by creating separation between the most urbanized labor markets (see Figure 3) from the rest. Within region contributions, aside from the Northeast, were of roughly similar magnitudes, with the exception of high contributions of the US South to national wage distributions. ${ }^{15}$ Little substantive variation across urbanization levels are observed, aside from low contributions for geographical mobility in the most urban commuting zones. ${ }^{16}$ In total, results show that the recent increase of divergence, driven partially through inequality-inducing geographical mobility and overall increases to inequality, were channeled through growth of inequality levels across commuting zones of differing levels of urbanization. Convergence was an interregional phenomenon particularly featuring the US South, while the contemporary upswing of inequality divergence places greater importance on the separation of commuting zones based on urbanization status.

\section{Discussion and Conclusion}

In this paper I assessed the long-run historical trends of local labor market inequality convergence. While trends among central tendencies are well studied, less is known about the "inequality of inequalities." I therefore use 22 waves of Census and American Community Survey data to construct wage inequality information in commuting zones between 1940 and 2019 and apply variance decomposition and

\footnotetext{
${ }^{15}$ As shown in Figure 2, the US South has relatively low variance, but has been growing at a rapid rate beginning in 1980.

${ }^{16}$ This contrasts with the high mean inequality levels of this group.
} 
counterfactual techniques to assess the national, regional, and local inputs for overall trends of sigma divergence.

Macrolevel trends show that inequality sigma divergence follows a u-shaped pattern, with the variance of inequality across local labor markets declining substantially between 1950 and 1990 . Thereafter, sigma divergence has increased to levels of the previous highwater marks found in the 1940 and 1950 Census waves. This inequality variance growth lagged after that of per capita income by one to two decades (Amos 2014; Manduca 2019). Thus, the modern era is not only one of increasing inequality across individuals, firms, and states, but of greater variability of inequality levels across labor markets as well.

What explains this u-shaped trend in the inequality of inequalities? The inequality convergence of the mid and late $20^{\text {th }}$ century was broadly shared across regions, across urbanization levels, reduced regional differences, and occurred largely through the geographical relocation of wage levels that primarily channeled into reducing interregional inequality differences. With one significant caveat, discussed, the era of 1950-1990 was one of wide-ranging spatial equalization, with mechanisms across national, regional, and local levels largely moving in concert to generate similarity of inequality levels across local labor markets.

A critical caveat is how inequality levels equalized across US regions during this era. Inequality convergence, or equalizing inequality levels across places, does not necessarily occur through the lowering of inequality levels among highly unequal local labor markets. My results show that the substantial decline of inequality during the 1940s largely occurred outside the US South, and that afterwards other regions "caught up" to the US South through increasing wage inequality levels. This is in stark contrast to historical development studies documenting how the US South caught up through increasing levels of development and mean income to the rest of the country during this same period (Shulman 1994, Wright 2013, Baker 2020). Inequality and developmental convergence during this era occurred through contrasting regional trajectories. 
The recent upswing of inequality divergence has occurred through a broadly shared trend of divergence within regions and areas defined by urbanization. Yet the rise of inequality, particularly in the $21^{\text {st }}$ century, has occurred through several novel factors: geographical mobility and changes in the national wage distribution both contributing to inequality divergence-in contrast to their countervailing contributions through 1980, the Midwest retaining low average inequality levels (albeit historically high intraregional variance), and especially the emergence of highly urbanized areas as uniquely unequal places. The combination of these factors in an era where inequality has grown primarily because of the separation of top paid workers (Autor 2019) suggests that spatial polarization among a narrower and more geographically dispersed set of labor markets has become a central feature of contemporary inequality change. Once considered to be the engine of upward economic attainment and opportunity (Glaeser and Gottleib 2009, Moretti 2012), highly urbanized areas have clearly emerged as the engines of contemporary nation-level inequality growth.

This paper provides several important innovations for stratification research. Most essentially, results highlight the critical importance of spatial inequality for contemporary stratification. Spatial inequality scholars have documented the increased importance of the geographical distribution of economic resources and opportunities, highlighting the contribution of urban-rural differences, the devolution of social welfare to the local level, and uneven developmental trends (Lobao et al. 2007, Lobao et al. 2016, Lobao 2016). The current paper demonstrates the fundamentally spatial consequences of these mechanisms documented in the broader spatial inequality literature. The United States has undergone significant eras in which local labor markets move more or less apart from one another.

This paper highlights the relational nature of spatial inequality, as varying inequality trajectories result in overall variation of inequality levels across local labor markets. An emphasis on the relational nature of inequality across labor markets introduces a critical second moment of subnational spatial inequality studies. Many studies assess trends in mean inequality levels over time (Moller et al. 2009, VanHeuvelen 2018). Of course, mean variation implies divergence across local labor markets, yet this 
second moment of spatial inequality is rarely formally assessed. Furthermore, inequality variance does not necessarily directly follow mean inequality levels. Appendix materials include the macrolevel association between year-specific mean commuting zone inequality and year-specific commuting zone inequality variance, showing that the two do not simply follow a linear relationship. High inequality variance occurs in both high and low mean inequality eras. Inequality variance thus represents a distinct outcome that is not fully reducible to the study of mean inequality levels.

Insofar as inequality produces consequential social, political, and economic outcomes (Mijs and Roe 2021), the current research has significant implications. The return of high inequality variance alongside high mean levels of inequality suggests a devolution of inequality-based social problems across local areas. Addressing any social problem associated with inequality could more reasonably be conceptualized as a national or regional problem in the latter half of the $20^{\text {th }}$ century. Today, the heightened variation of inequality across local labor markets suggests that particular problems associated with either too much or too little inequality cannot easily be reconciled into a larger geographically targeted project to address inequality (Austin et al. 2018). In some ways, this trajectory mirrors the devolution of federal policy to the local level documented by Lobao, among others (2016). Whether local inequality can be adequately addressed by local policymakers, given the potential mobility of capital and labor in response to local policy decisions, remains to be seen.

This paper has several limitations to motivate future research. Most straightforwardly, I focus on prefisc wage inequality. Although this moment of inequality is central for much of the earnings that individuals accumulate during their careers, it necessarily sidesteps questions of within-household pooling, alternative income sources, and the contribution of national and local tax and transfer regimes. To what extent do divergence measures vary across different definitions of earnings and income, and to what extent can policy changes to taxes and transfers adjust these divergence trends? Future research on these topics is needed. 
The current paper focused on the overall observed wage inequality levels, tracking these as they actually occurred. Yet this approach necessarily tables the unique contributions of the advances, retrenchments, and stagnations in the social and economic standing of women, racial and ethnic minorities, and immigrants during the period studied. Perhaps some of the convergence of inequality across the $20^{\text {th }}$ century masks differential access to paid work of social groups across time. Future work on this topic is needed.

The measure I use for urbanization is useful for its time-invariance, but work by Moretti (2012), Fritz and Manduca (2021), and others show critical dimensions of metropolitan areas that can be used to better differentiate diversion. These include the concentration of educated workers, local housing prices, and local measures of economic complexity. Such work would provide a useful extension to the trends documented here.

This research documents the long run u-shaped pattern of the "inequality of inequalities."

Following a broadly shared decline of divergence through the $20^{\text {th }}$ century, spatial inequality in the United States today faces novel and aligned mechanisms that are generating levels of inequality divergence not seen in the past 80 years. 


\section{Work Cited}

Amos Jr, Orley. 2014. "Evidence of Increasing Regional Income Variation in the United States: 19692006." Modern Economy, 5(05), 520.

Austin, Benjamin, Edward Glaeser, and Lawrence H. Summers. 2018. "Saving the Heartland: PlaceBased Policies in 21st Century America." In Brookings Papers on Economic Activity, edited by Janice Eberly and James Stock, 151-232. Washington DC: Brookings Institution Press

Autor, David H., David Dorn, and Gordon H. Hanson. 2016. "The China shock: Learning from labormarket adjustment to large changes in trade." Annual Review of Economics 8: 205-240.

Acemoglu, Daron, and David Autor. 2011. "Skills, Tasks and Technologies: Implications for Employment and Earnings." In Handbook of Labor Economics, Vol. 4, edited by Orley Ashenfelter and David Card, 1043-1171. Amsterdam: Elsevier-North Holland.

Autor, David, H., David Dorn, and Gordon H. Hanson., 2013. The China syndrome: Local labor market effects of import competition in the United States. American Economic Review, 103(6), pp.2121-68.

Autor, David, 2019. Work of the Past, Work of the Future. National Bureau of Economic Research.

Baccini, Leonardo, and Stephen Weymouth. 2021. "Gone for Good: Deindustrialization, white voter backlash, and US presidential voting." American Political Science Review: 1-18.

Baker, Regina S. 2020. "Why is the American South poorer?." Social Forces 99(1): 126-154.

Barro, Robert J., 2008. Inequality and growth revisited (No. 11). ADB Working paper series on regional economic integration.

Barro, Robert J., and Xavier Sala-i-Martin. 1990. "Economic Growth and Convergence across the United States.” NBER Working Paper, no. 3419.

Baumol, William J. 1986. "Productivity Growth, Convergence, and Welfare: What the Long-Run Data Show." The American Economic Review 76(5):1072-1085

Beckfield, Jason. 2009. "Remapping inequality in Europe: The net effect of regional integration on total income inequality in the European Union." International Journal of Comparative Sociology. 50, no. 5-6: 486-509.

Berry, Christopher R., and Edward L. Glaeser. 2005. "The Divergence of Human Capital Levels Across Cities." Papers in Regional Science 84(3): 407-444

Catron, Peter. 2019. "The citizenship advantage: Immigrant socioeconomic attainment in the age of mass migration." American Journal of Sociology. 124(4): 999-1042.

Chetty, Raj, and Nathaniel Hendren. 2018. "The impacts of neighborhoods on intergenerational mobility II: County-level estimates." The Quarterly Journal of Economics. 133(3): 1163-1228.

Clark, Robert, 2019. The Goldilocks effect: Convergence in national income distributions, 1990 2015. Social science research, 79, pp.141-159.

De La Roca, Jorge, and Diego Puga. 2017. "Learning by working in big cities." The Review of Economic Studies. 84(1): 106-142. 
Diamond, Rebecca. 2016. “The Determinants and Welfare Implications of U.S. Workers' Diverging Location Choices by Skill: 1980-2000.” American Economic Review 106(3):479-524

DiNardo, John, Nicole M. Fortin, and Thomas Lemieux. 1996. "Labor market institutions and the distribution of wages, 1973-1992: A semiparametric approach." Econometrica. 1001-1044.

Dorn, David. 2009. "Essays on Inequality, Spatial Interaction, and the Demand for Skills." University of St. Gallen.

Dube, Arindrajit. 2019. "Minimum wages and the distribution of family incomes." American Economic Journal: Applied Economics 11(4): 268-304.

Florida, Richard, and Charlotta Mellander. 2016. The Geography of Inequality: Difference and Determinants of Wage and Income Inequality across US Metros." Regional Studies, 50(1): 79-92.

Fritz, Benedikt, and Robert Manduca. 2021. "The economic complexity of US metropolitan areas." Regional Studies: 1-12.

Ganong, Peter and Shoag, Daniel, 2017. Why has regional income convergence in the US declined? Journal of Urban Economics, 102:76-90.

Giannone, Elisa. 2017. "Skill-Biased Technical Change and Regional Convergence.” Working Paper

Goldin, Claudia and Margo, Robert A., 1992. The great compression: The wage structure in the United States at mid-century. The Quarterly Journal of Economics, 107(1):1-34.

Glaeser, Edward L., and Joshua D. Gottlieb. 2009. "The Wealth of Cities: Agglomeration Economies and Spatial Equilibrium in the United States." Journal of Economic Literature 47(4):983-1028

Harrison, Bennett and Barry Bluestone. 1988. The Great U-Turn: Corporate Restructuring and the Polarizing of America. Basic Books.

Hoffmann, Florian, David S. Lee, and Thomas Lemieux. 2020. "Growing income inequality in the United States and other advanced economies." Journal of Economic Perspectives 34(4): 52-78.

Hout, Michael, 2016. Money and morale: Growing inequality affects how Americans view themselves and others. The ANNALS of the American Academy of Political and Social Science. 663(1): 204-228.

Iceland, John. 2013. Poverty in America: A handbook. Univ of California Press.

Kuznets, Simon. 1955. "Economic Growth and Income Inequality.” American Economic Review 45: $1-28$.

Lindert, Peter and Jeffrey Williamson, 2016. Unequal gains: American growth and inequality since 1700. Juncture, 22(4):276-283.

Lobao, Linda M., Gregory Hooks, and Ann R. Tickamyer, eds. 2007. The sociology of spatial inequality. SUNY Press.

Lobao, Linda. 2016. "The Sociology of Subnational Development: Conceptual and Empirical Foundations." In The Sociology of Development Handbook, edited by Gregory Hooks, Shushanik Makaryan, and Paul Almeida, 265-92. Oakland, California: University of California Press. 
Lobao, Linda. 2016. "The rising importance of local government in the United States: Recent research and challenges for sociology." Sociology Compass 10(10): 893-905.

Logan, John R. 2012. "Making a Place for Space: Spatial Thinking in Social Science.” Annual Review of Sociology 38(1):507-24

Manduca, Robert. 2019. The contribution of national income inequality to regional economic divergence. Social Forces, 98(2): 622-648.

Marsh, Robert. 2007. “A New Test of Convergence Theory.” Comparative Sociology 6: 251 -294.

Mazzolari, Francesca, and Giuseppe Ragusa. 2013. "Spillovers from high-skill consumption to low-skill labor markets." Review of Economics and Statistics. 95(1): 74-86.

McCall, Leslie and Christine Percheski. 2010. "Income Inequality: New Trends and Future Directions." Annual Review of Sociology. 36: 329-347.

Meyer, John, John Boli-Bennett, and Christopher Chase-Dunn. 1975. "Convergence and Divergence in Development." Annual Review of Sociology 1: 223 - 246

Mijs, Jonathan JB, and Elizabeth L. Roe. 2021. "Is America coming apart? Socioeconomic segregation in neighborhoods, schools, workplaces, and social networks, 1970-2020." Sociology Compass. 15:6. 1-16.

Milanovic, Branko. 2016. Global inequality: A new approach for the age of globalization. Harvard University Press.

Moller, Stephanie, Alderson, Arthur S. and Nielsen, Francois, 2009. Changing patterns of income inequality in US counties, 1970-2000. American Journal of Sociology, 114(4): 1037-1101.

Molloy, Raven, Christopher L. Smith, and Abigail Wozniak. 2017. Job changing and the decline in longdistance migration in the United States. Demography, 54(2): 631-653.

Moretti, Enrico. 2012. The New Geography of Jobs. Boston: Houghton Mifflin Harcourt

Mouw, Ted, and Arne L. Kalleberg. 2010. "Occupations and the structure of wage inequality in the United States, 1980s to 2000s." American Sociological Review 75(3): 402-431.

Neckerman, Kathryn M. and FLorencia Torche. 2007. "Inequality: Causes and Consequences." Annual Review of Sociology. 33: 335-357.

Neumayer, Eric. 2003. "Beyond Income: Convergence in Living Standards, Big Time.” Structural Change and Economic Dynamics 14: 275 - 296.

Nielsen, Francois and Alderson, Arthur S., 1997. The Kuznets curve and the great U-turn: income inequality in US counties, 1970 to 1990. American Sociological Review.12-33.

Ostry, Jonathan D., Prakash Loungani, and Andrew Berg. 2019. Confronting inequality: How societies can choose inclusive growth. Columbia University Press.

Reardon, Sean F., \& Bischoff, Kendra. 2011. Income inequality and income segregation. American Journal of Sociology, 116(4): 1092-1153.

Schulman, Bruce. 1994. From Cotton Belt to Sunbelt: Federal Policy, Economic Development, and the Transformation of the South, 1938-1980. Duke University Press. 
Shorrocks, Anthony. 2013. "Decomposition Procedures for Distributional Analysis: A Unified Framework Based on the Shapley Value." Journal of Economic Inequality 11(1): 99.

Storper, Michael. 2018. Separate worlds? Explaining the current wave of regional economic polarization. Journal of Economic Geography, 18(2): 247-270.

Tolbert, Charles M., and Molly Sizer. 1996. "US Commuting Zones and Labor Market Areas: A 1990 Update."

VanHeuvelen, Tom., 2018. Recovering the missing middle: a mesocomparative analysis of within-group inequality, 1970-2011. American Journal of Sociology, 123(4), pp.1064-1116.

VanHeuvelen, Tom and Katherine Copas. 2019. The Geography of Polarization, 1950 to 2015. RSF: The Russell Sage Foundation Journal of the Social Sciences, 5(4): 77-103.

Volscho Jr, Thomas. 2005. Minimum wages and income inequality in the American states, 19602000. Research in Social Stratification and Mobility. 23: 343-368.

Western, Bruce, and Deirdre Bloome. 2009. "Variance Function Regressions for Studying Inequality." Sociological Methodology 39(1): 293-326.

Western, Bruce and Jake Rosenfeld. 2011. Unions, norms, and the rise in US wage inequality. American Sociological Review, 76(4): 513-537.

Wilkinson, Richard, and Kate Pickett. 2011. The spirit level: Why greater equality makes societies stronger. Bloomsbury Publishing USA.

Wright, Gavin. 2013. Sharing the Prize: The Economics of the Civil Rights Revolution in the American South. Harvard University Press.

Young, Andrew T., Matthew J. Higgins, and Daniel Levy. 2008. "Sigma convergence versus beta convergence: Evidence from US county-level data." Journal of Money, Credit and Banking 40(5): 10831093. 


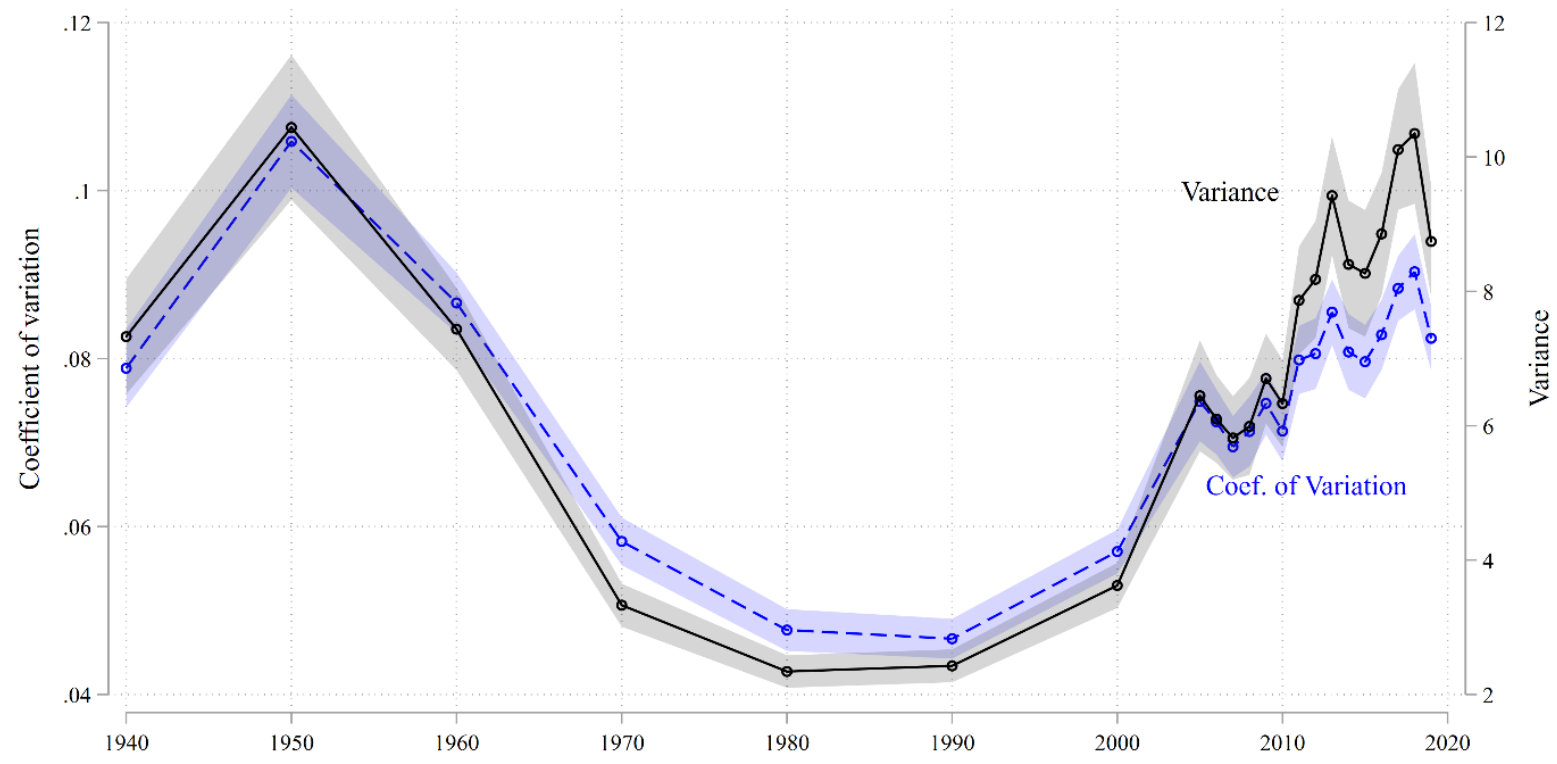

Figure 1: Macrolevel Sigma Divergence Trends

Notes: Sigma divergence measures calculated from wage Gini coefficients from 722 commuting zones from contiguous United States. Data from 1940-2000 Census longform and 2005-2019 American Community Survey. Shaded areas represent bootstrapped 95\% confidence intervals. 

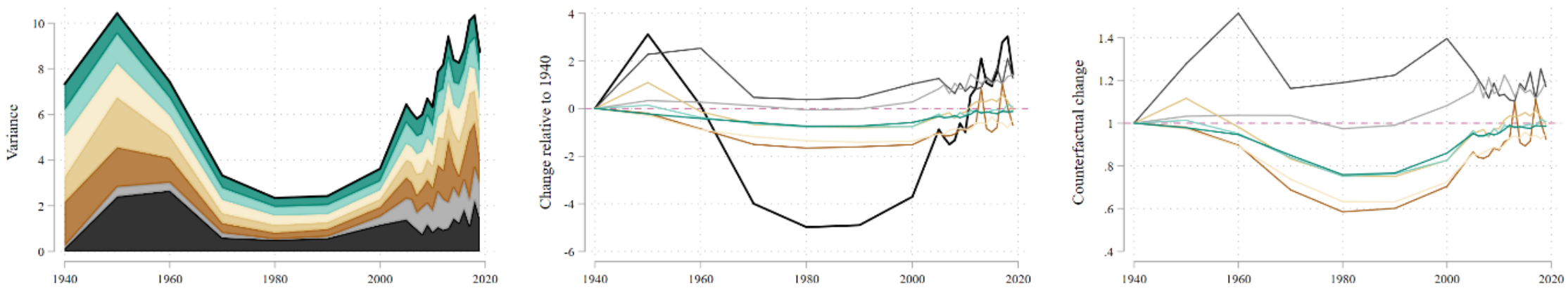

- Between Region

- Between Urban

- Within Least Urban

W Within Low

Within Mid

_ Within High

- Within Most Urban
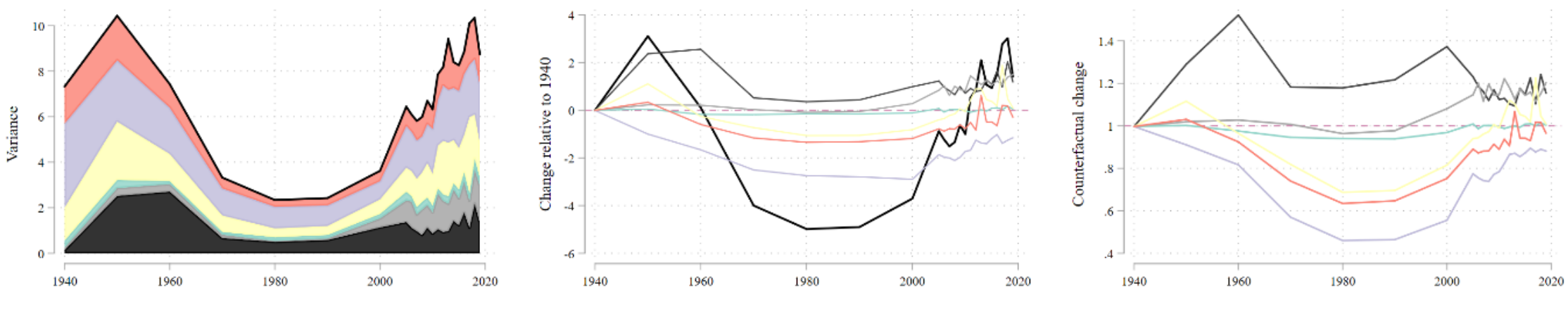

- Total variance

- Between Region

- Between Urban

- Within Northeast

Within Midwest

Within South

— Within West

\section{Figure 2: Variance Decomposition by Region and Urbanization}

Notes: Left panels: Total year-specific variance decomposed into between region, between urbanization, and within-region or -urbanization components. Middle panel: change relative to 1940 of total variance (dark black line), between region, between urbanization, and within- region or urbanization components. Right panel: ratio of observed variance and counterfactual variance levels holding one component of between region, between urbanization, and within-region or urbanization to 1940 levels. Greater difference from 1 indicates larger relative contribution of component change to total variance trends. See Methods section for formula to compute variance decomposition. Data are wage Gini coefficients from 722 commuting zones from contiguous United States from 1940-2000 Census longform and 2005-2019 American Community Survey. 

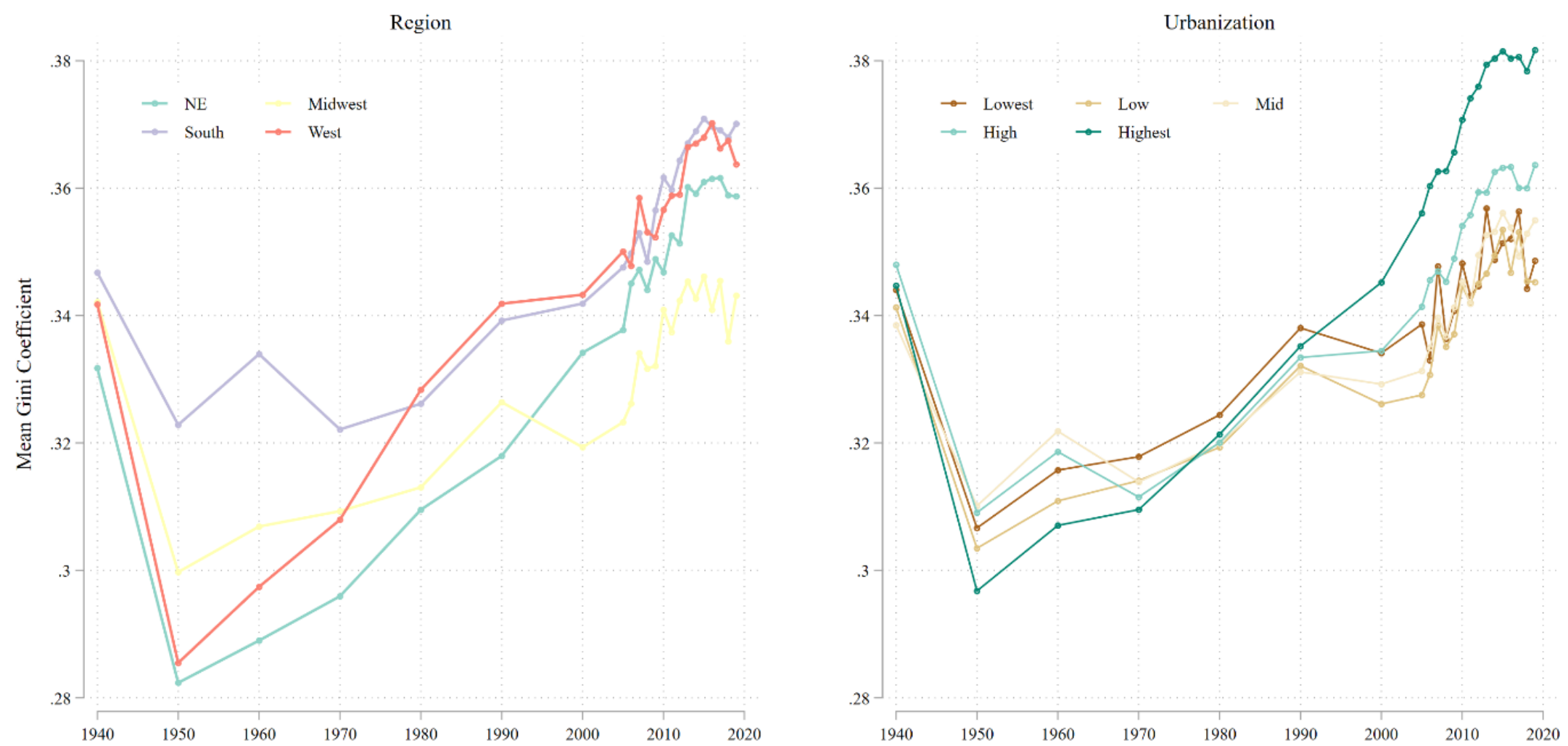

Figure 3: Mean Inequality Levels by Region and Urbanization Status

Notes: Wage Gini coefficients from 722 commuting zones from contiguous United States. Data from 1940-2000 Census longform and 2005-2019 American Community Survey. 
Simulated changes to wage inequality dispersion
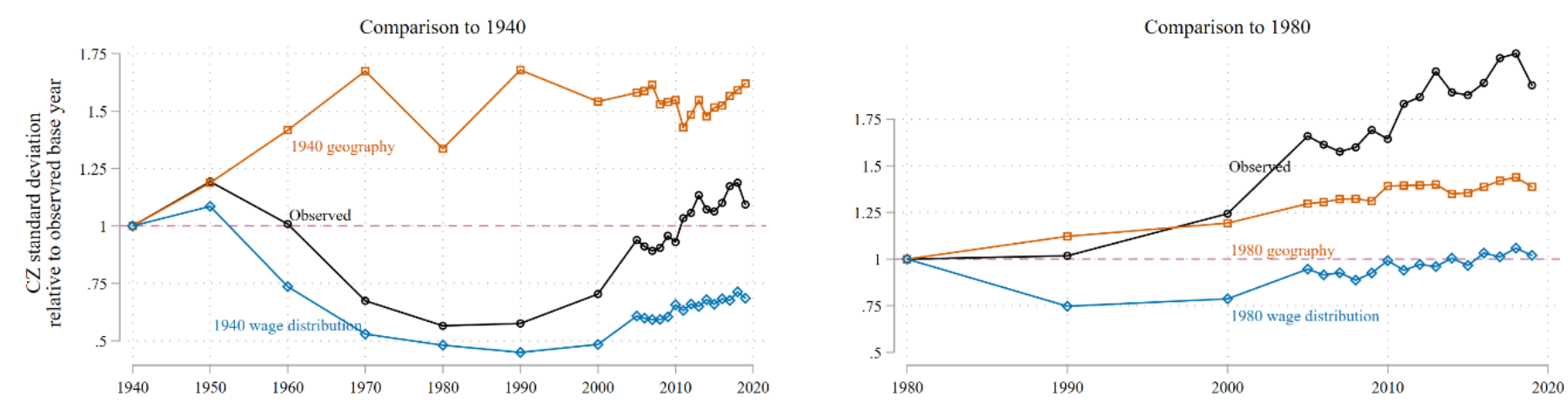

Comparison of simulated and observed wage inequality dispersion by year
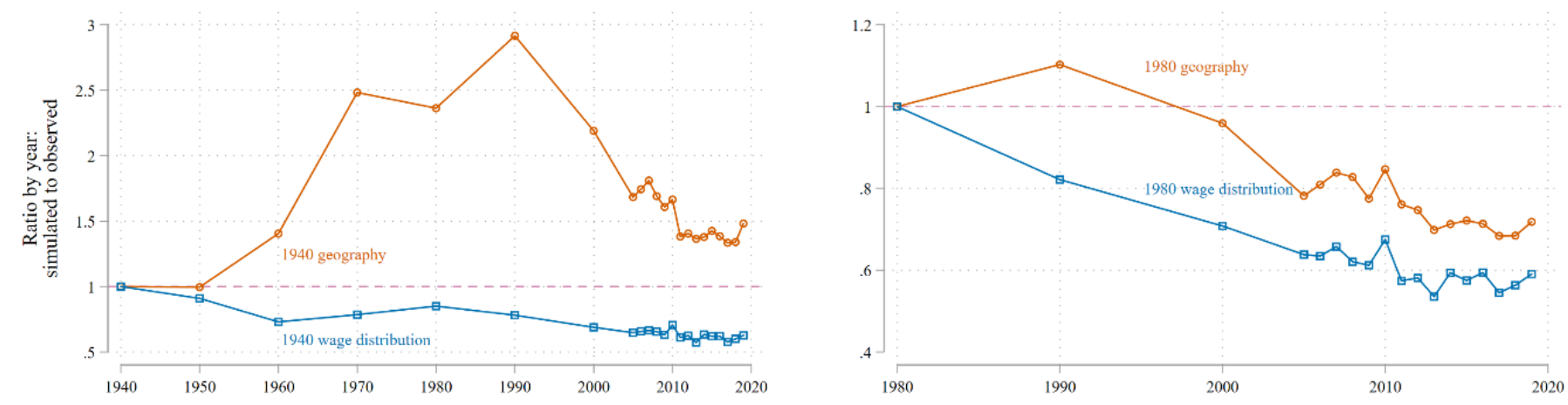

\section{Figure 4: Counterfactual Simulations, Geographical Mobility and National Wage Inequality Contributions to Sigma Divergence Trends}

Notes: Top row: Comparison of observed and counterfactual trends holding mobility and wage distribution to 1940 (left columns) or 1980 (right columns) baseline. Bottom row: Relative difference between observed and counterfactual sigma divergence measures, measured as the year-specific ratio of counterfactual over observed trends. Geography lines refer to holding national wage quantile geographic distribution to baseline periods. Wage distribution lines refer to holding national wage quantiles relative to the mean wage at baseline periods. See Methods section for more detail. 
Table 1: Counterfactual Decomposition: 1940-1980

\begin{tabular}{|c|c|c|c|c|c|c|c|c|c|c|c|c|}
\hline & Total & Bety & een & & Within: Re & ion & & & Within & Urbar & ization & \\
\hline & Variance & Region & Urban & Northeast & Midwest & South & West & $\begin{array}{l}\text { Least } \\
\text { Urban }\end{array}$ & $\begin{array}{l}\text { Less } \\
\text { Urban }\end{array}$ & Mid & $\begin{array}{l}\text { More } \\
\text { Urban }\end{array}$ & $\begin{array}{l}\text { Most } \\
\text { Urban }\end{array}$ \\
\hline \multicolumn{13}{|l|}{ Change: 1940 to 1980} \\
\hline Observed & -4.98 & 0.36 & -0.08 & -0.14 & -1.05 & -2.74 & -1.34 & -1.22 & -0.77 & -1.49 & -0.78 & -1.05 \\
\hline Geography CF & 5.76 & 3.51 & 0.73 & 0.22 & 0.93 & -0.05 & 0.43 & 0.62 & 0.49 & -0.67 & 0.69 & 0.39 \\
\hline Distribution CF & -5.63 & 0.20 & -0.08 & -0.21 & -1.11 & -3.07 & -1.38 & -1.26 & -0.91 & -1.57 & -0.87 & -1.18 \\
\hline Geography - Observed & 10.74 & 3.15 & 0.81 & 0.36 & 1.98 & 2.70 & 1.77 & 1.84 & 1.26 & 0.82 & 1.47 & 1.44 \\
\hline Percent Contribution & & 29.30 & 7.54 & 3.39 & 18.44 & 25.10 & 16.51 & 17.14 & 11.69 & 7.62 & 13.67 & 13.40 \\
\hline $\begin{array}{l}\text { Distribution - } \\
\text { Observed }\end{array}$ & -0.65 & -0.16 & 0.00 & -0.07 & -0.06 & -0.33 & -0.04 & -0.04 & -0.14 & -0.08 & -0.09 & -0.13 \\
\hline Percent Contribution & & 24.95 & -0.30 & 10.48 & 8.82 & 50.50 & 5.93 & 6.53 & 22.15 & 12.20 & 14.48 & 20.41 \\
\hline
\end{tabular}

Notes: Geography and Distribution counterfactuals (CF) refer the counterfactuals visualized and discussed in Figure 4. Variance decomposition refers to methods used in Figure 2. Bottom rows show percent contribution of decomposition components to difference between observed and counterfactual trends. Larger absolute differences indicate that a particular decomposition component contributed a greater proportion to counterfactual change. 
Table 2: Counterfactual Decomposition: 1980-2019

\begin{tabular}{|c|c|c|c|c|c|c|c|c|c|c|c|c|}
\hline & \multirow{2}{*}{$\begin{array}{c}\text { Total } \\
\text { Variance }\end{array}$} & \multicolumn{2}{|c|}{ Between } & \multicolumn{4}{|c|}{ Within: Region } & \multicolumn{5}{|c|}{ Within: Urbanization } \\
\hline & & Region & Urban & Northeast & Midwest & South & West & $\begin{array}{l}\text { Least } \\
\text { Urban }\end{array}$ & $\begin{array}{l}\text { Less } \\
\text { Urban }\end{array}$ & Mid & $\begin{array}{l}\text { More } \\
\text { Urban }\end{array}$ & $\begin{array}{l}\text { Most } \\
\text { Urban }\end{array}$ \\
\hline \multicolumn{13}{|l|}{ Change: 1980 to 2019} \\
\hline Observed & 6.40 & 0.83 & 1.59 & 0.20 & 1.16 & 1.59 & 1.05 & 0.91 & 0.77 & 0.89 & 0.86 & 0.57 \\
\hline Geography CF & 2.17 & 0.33 & 0.05 & 0.18 & 0.37 & 0.99 & 0.25 & 0.29 & 0.41 & 0.42 & 0.33 & 0.35 \\
\hline Distribution CF & 0.12 & 0.60 & 0.21 & -0.09 & -0.05 & -0.47 & -0.07 & 0.00 & -0.02 & -0.14 & -0.16 & -0.37 \\
\hline \multicolumn{13}{|l|}{ Geography - } \\
\hline Observed & -4.23 & -0.50 & -1.53 & -0.02 & -0.79 & -0.60 & -0.80 & -0.62 & -0.36 & -0.47 & -0.54 & -0.23 \\
\hline Percent Contribution & & 11.79 & 36.23 & 0.37 & 18.76 & 14.08 & 18.97 & 14.64 & 8.49 & 11.12 & 12.65 & 5.36 \\
\hline Distribution - & & & & & & & & & & & & \\
\hline Observed & -6.28 & -0.23 & -1.37 & -0.29 & -1.22 & -2.07 & -1.13 & -0.91 & -0.79 & -1.03 & -1.02 & -0.95 \\
\hline Percent Contribution & & 3.59 & 21.87 & 4.64 & 19.35 & 32.87 & 17.93 & 14.44 & 12.61 & 16.41 & 16.31 & 15.08 \\
\hline
\end{tabular}

Notes: Geography and Distribution counterfactuals (CF) refer the counterfactuals visualized and discussed in Figure 4. Variance decomposition refers to methods used in Figure 2. Bottom rows show percent contribution of decomposition components to difference between observed and counterfactual trends. Larger absolute differences indicate that a particular decomposition component contributed a greater proportion to counterfactual change. 
Appendix materials:

Subnational Inequality Divergence 
Appendix Table 1: Example Commuting Zones by urbanization level

\begin{tabular}{|c|c|}
\hline \multirow{2}{*}{\multicolumn{2}{|c|}{ Hiohost urhanization }} \\
\hline & Middle urban, cont. \\
\hline New York, NY & Idabel, OK \\
\hline Chicago, IL & Eufaula, BA \\
\hline Newark, NJ & Billings, MT \\
\hline Philadelphia, PA & Ada, OK \\
\hline Boston, MA & Enid, OK \\
\hline \multicolumn{2}{|l|}{ Decatur, IL } \\
\hline Dover, DE & Low urban \\
\hline Columbus, GA & Missoula, MT \\
\hline Elmira, NY & Storm Lake, IA \\
\hline \multirow[t]{2}{*}{ Portland, ME } & Bainbridge, GA \\
\hline & San Angelo, TX \\
\hline Moderate & Batesvill, AR \\
\hline Beaumont, TX & Parkston, SD \\
\hline Montgomery, AL & Milbank, MN \\
\hline Wilson, NC & Vernon, TX \\
\hline Lafayette, IN & Marysville, KS \\
\hline Colorado Springs, CO & Liberal, KS \\
\hline \multicolumn{2}{|l|}{ Bartlesville, KS } \\
\hline Yakima, WA & Least urban \\
\hline Paris, TX & Alamosa, CO \\
\hline Winchester, VA & Ontario, OR \\
\hline \multirow[t]{2}{*}{ Talladega, AL } & Pecos, TX \\
\hline & Oak Bluffs, MA \\
\hline Middle urban & Woodward, OK \\
\hline Muskogee, OK & Jordan, MT \\
\hline Easton, MD & Van Horn, TX \\
\hline Jasper, AL & Ekalaka, SD \\
\hline Longview, WA & Loa, UT \\
\hline Fairmont, MN & Murdo, SD \\
\hline
\end{tabular}

Note: Highest and lowest urbanization values from each category listed 


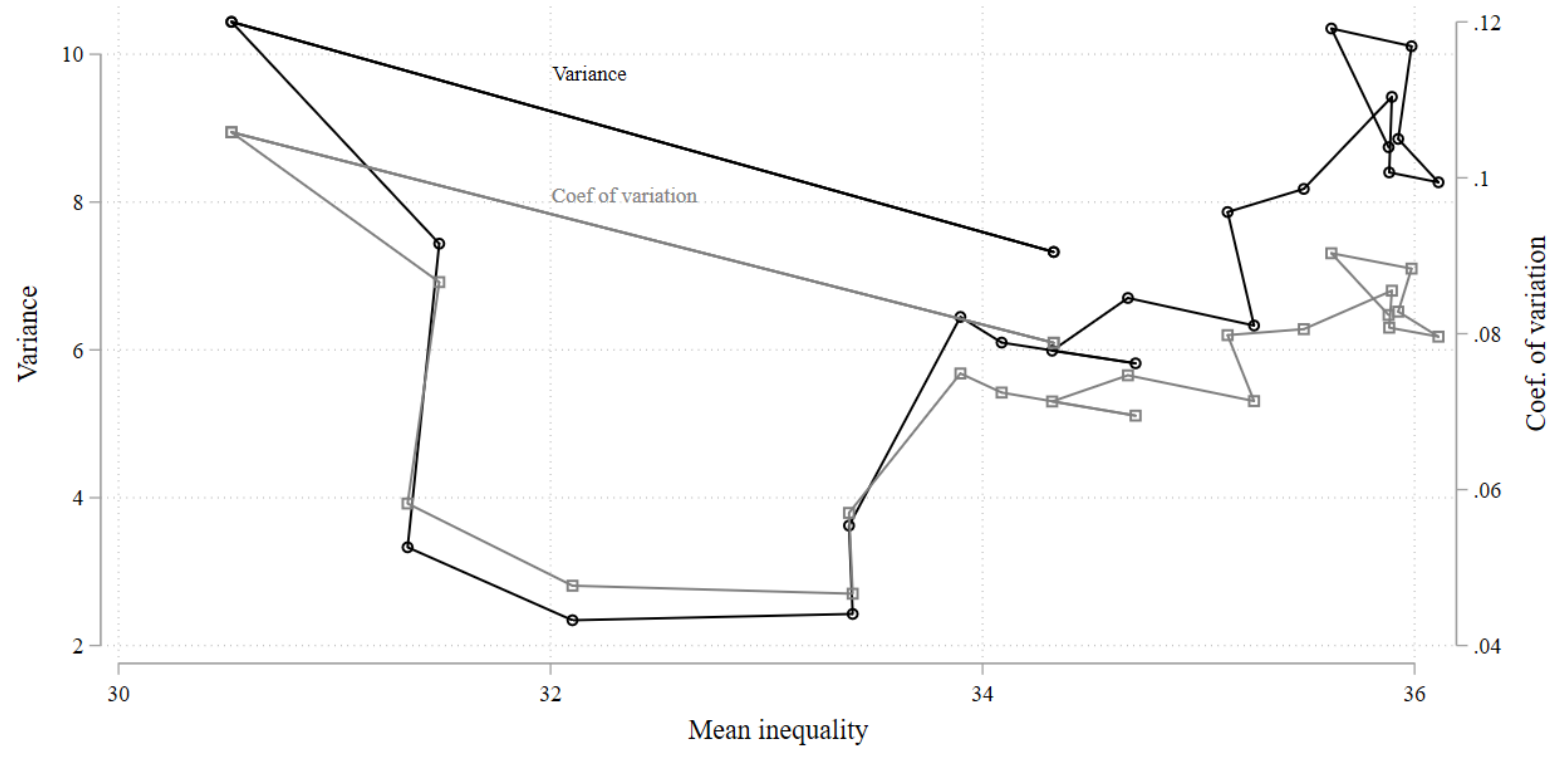

Appendix Figure 1: Relationship between macrolevel mean wage inequality and overall sigma divergence measures 


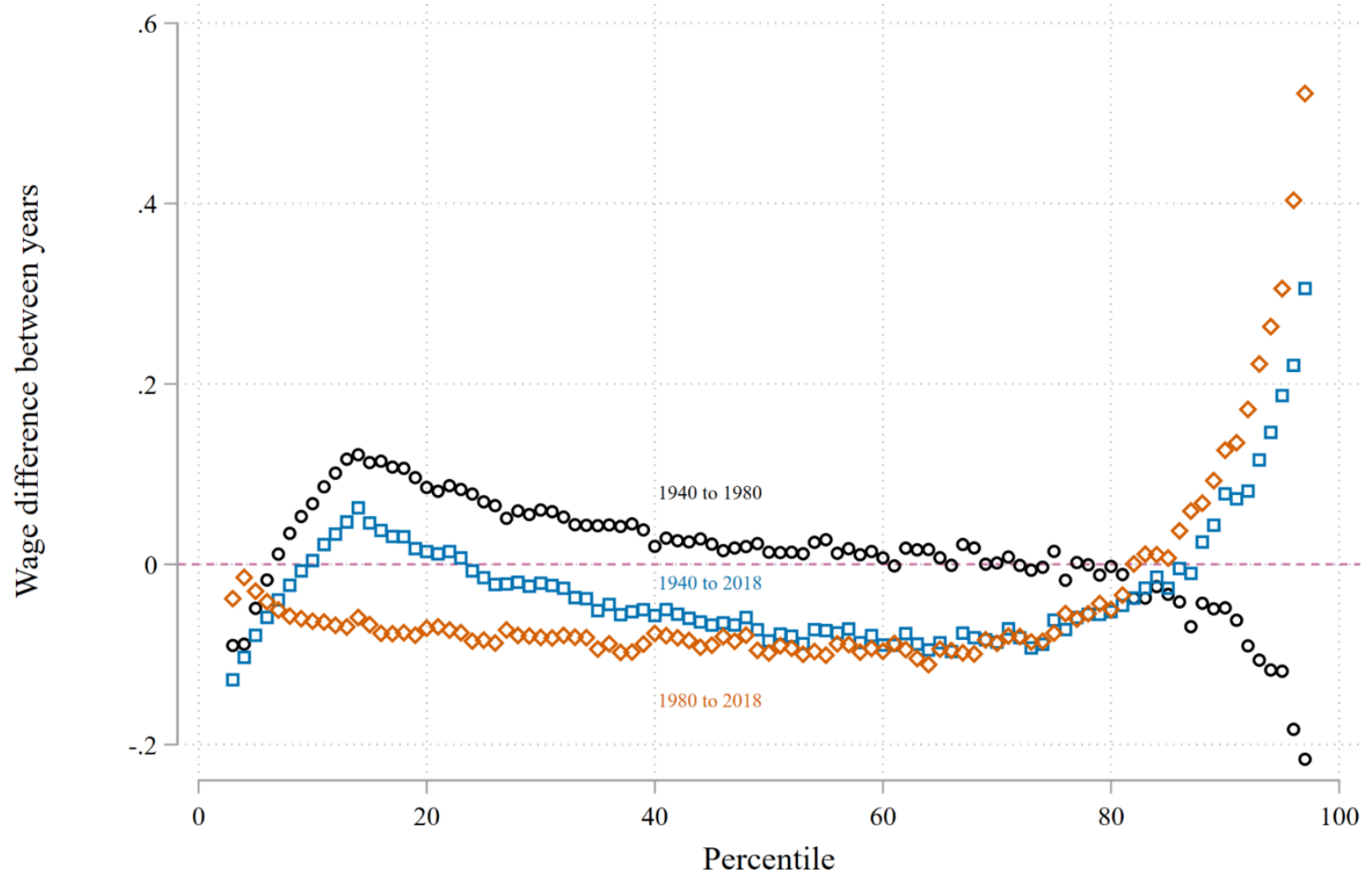

Appendix Figure 2: Change in wage percentile levels between years, 1940 to 1980 to 2018

Notes: Values above zero indicate wage growth at specific percentiles. 